\title{
Peer-Teaching of Computer Skills with Cooperative Learning in Macao: Work in Progress
}

\author{
Kelvin Wong, Ana Cristina Neve, João Negreiros \\ University of Saint Joseph, Rua de Londres, 16 - Macao, China
}

\begin{abstract}
University students in Macao are required to attend computer literacy courses to develop their basic skill levels and knowledge as part of their mastery foundations. To be effective, such courses, which are very staff intensive and require access to expensive equipment and software, demand high levels of individual teaching. Still, teachers frequently complain about the weak IT skills of many courses. This on-going research proposes an enhanced model for designing and delivering computer literacy courses based on peer-tutoring to improve student outcomes. It is expected to ensure that the curriculum content, learning styles and assessment procedures are properly aligned and fully understood by both instructors and students to achieve high quality results. In Macao, most students hold a Confucian Heritage Cultural (CHC) background and, thus, it is expected/ we anticipate that the present study will provide new insights into the relation between $\mathrm{CHC}$ and peer-tutoring.
\end{abstract}

\section{Introduction}

Broadly speaking, computer literacy encompasses the knowledge and skills needed to use computers to accomplish daily tasks and achieve one's goals. This includes a wide knowledge such as how to use word processing and presentation software. Spreadsheet and database software, Internet and blend online activities are also components of any typical computer course syllabus.

Computer literacy is also a catch phrase, a popular slogan that whets the appetite of politicians and academics [1]. It can mean a hundred different things; there is not just a single but rather a large variety of concepts involved. One decade later, [2] noted that ambiguity had been recognized in the development of the computer literacy curriculum. This ambiguity has resulted in confusion on how to define it at university level. [2] also made the observation that most hardware and software being used to educate people would become obsolete in a fast way, so it is better to teach computer concepts instead of specifics. Towards the end of the 1990s, most discussions about computer literacy focused on computer literacy education where the end-user could experiment with most programs, but lacked programming knowledge [3].
Certainly, the precise definition varies considerably. [4] believe that computer and information technology proficiencies are perceived to be critical among employees. Confirming this view, [5] realize that computer literacy has been recognized as an essential skill in today's competitive job market. Also, competencies for graduates have changed from mastering of information to solve complex problems, including communicating clearly and working collaboratively with people from different cultural and social backgrounds [6]. In order to meet this demand from the industrial and commercial sectors, universities are teaching these skills as a fundamental part of any undergraduate program [7].

These expectations have also changed and, at the same time, there is an evidence that recruiters do not only ask for qualifications, employment experience or interests, but also computer skills [8]. As well, preparing students for today's knowledge-rich society demands different teaching and learning methodologies [9]. For the majority of faculties, this results in a reform of their education environments in developing young people to become good citizens, critical thinkers and productive workers $[10,11]$.

Today, computer literacy can be broken down into two components: awareness and competence [12]. They believe that multi-dimension of skills, including computation and interpersonal skills, are usually demanded by industries for many professions (business operations and top management, for example). [12] report that universities periodically update their IT curricula based on the recommendations made by the IT educators, practitioners and other recruiters. Therefore, it would be reasonable to look for standards that industry recognizes worldwide, such as ECDL and ICDL, CLAIT, Microsoft Digital Literacy Standard Curriculum and ISTE.

All of them hold public examinations for different levels of computer literacy competences. These recognized standards provide similar learning objectives, which are based on several contexts. ECDL and ICDL, for instance, share similar learning aims, which include standards and guidelines that have been developed at national, state and local levels for elementary, secondary and higher education [13]. The learning aims published by the Oxford Cambridge and RSA Examinations are designed to provide candidates with acknowledge of standard IT hardware and software and familiarity 
with a range of different software applications. The University of Cambridge International Examination has six similar goals (CIE, 2011). ISTE provides a different curriculum, which is also internationally recognized [14].

Although a common international standard can be obtained from this effort, [15] reported that during the learning process, students are easily too often reluctant learners. They may also encounter cognitive overload during the learning process due to the ineffective teaching provision [15], [16], [17]. So, what can be done to overcome this situation?

By facing this difficulty, the present research proposal highlights previous studies concerning the adoption of peer-tutoring to effectively respond to student's demands without increasing the overall course costs and its impact on teachers' workload, including computer literacy, teaching environments and methods of delivery. Henceforth, the following two sections single out peer-tutoring and constructivism as a particularly powerful form of team teaching and learning, outlining the effects on students and tutors. Section four underlines Macao, China, problems towards computer literacy as a subject in today's universities while sections five and six focus on the key characteristics of the Confucian Heritage Culture (CHC) and cognitive scaffolding, respectively. Section seven depicts the overall research action to be taken at IFT (Instituto de Formação Turística) and USJ (Universidade de São José). Finally, some inferences and expectations are stressed in the last section.

\section{Peer-tutoring}

Peer-tutoring is a type of cooperative learning which has a long history of success in classrooms. According to [18], it is one way of making an active and social constructivist contribution to knowledge acquisition. A more capable peer with a supportive role is the tutor, whereas less experienced students receiving help from a tutor are called tutees. Thus, peer-tutoring is an intervention in which one student provides instruction or academic assistance to another student.

Research on this topic already reported before has demonstrated educational benefits. Studies have shown that peer-tutoring can improve performance in a variety of subjects such as reading and comprehensive abilities, improved computation and mathematical abilities and encouraging positive interaction with one another. [16], [18] achieved a high satisfaction rating for both tutors and tutees when using peer-tutoring because students are given much more flexibility for creating and owning their work. Moreover, during the process of learning, the tutees feel supported in conducting their own experiential learning [18]. They also specify that this practice creates pride and gives ownership to students who engage in peer-tutoring. Peer-tutoring further helps develop critical thinking skills within both tutors and tutees [19].

Experimental results published by [20] suggested that using this approach takes longer to cover less material than using traditional methods. However, [21] believe that the material can be covered more quickly, as long as the class has enough tutors, catering the students' needs for learning (particularly if the tutors are well experienced for leading groups of students). The work of [21] also reveals that with peer-tutoring, students' attendance rate drops over time. As a result, students display a lower retention rate. This happens because different peer-tutors naturally hold different perspectives on the subject and, henceforth, students may lose interest in the subject itself.

Although peer-tutoring is used worldwide, the style of using this method is somewhat different among countries, schools and even teachers. Given the variety of styles, it is likely to consist of key components, of which effective peer-tutoring can be deployed and thus better quality of learning can be found. One way of identifying key components is to analyze the common features of well-documented peer-tutoring methods. For example, class peertutoring emphasized equal opportunity involvement in peer learning, engaging all members of the educational community without exception [23]. Reciprocal peer-tutoring enables all involved to function as both helper and helped, avoiding any social divisiveness, according to perceived ability and status, whilst offering a richer apprenticeship for future involvement [24]. These two successful types of interventions were carried out in school and university settings and typically provided extra practice for basic skills such as reading, spelling or mathematics, but generally have not been used to replace teacher-directed instruction completely during the acquisition of new skills [25].

[26] Point out that class wide peer-tutoring holds benefits and it is a model that usually pairs two competent students with an ordinary student in the learning group settings, which has been found effective in improving students' attitude towards learning. On the other hand, reciprocal peer-tutoring (RPT) is usually managed among college students.

[27] Reported that under the RPT condition, students gained greater improvement in exam scores, reduced learning distress and achieved greater levels of student satisfaction. [28] Found that using peertutoring in higher education requires professional training and skills development. In medical schools; it has been found that $56 \%$ more students meet the learning objectives than those without the peertutors.

[29] Showed that applying this technique in different classes such as psychology can help students to gain a sense of responsibility as well as 
taking a more active role during the teaching and learning process. The teacher becomes a facilitator of learning, recognizing the autonomy of individuals and the responsibility they have towards their own personal growth and development.

[30] Found that students are encouraged to express ideas freely while tackling subject difficulties and can easily practice the relevant skills out of school time. Research shows that students who participated in peer-tutoring classrooms outperformed students in normal classrooms [31], [32].

Peer-tutoring seemed to be a non-threatening way to learn IT skills. Apart from this, students' selfmanagement skill increases as they work at their own pace, exchange knowledge and organize their work together in a small group. They can discover that when group members and peer-tutors remain the same, they become familiar with the teaching, learning and communication style. This will encourage students, hence, to learn through discussions.

\section{Constructivism}

Under the constructivist theory, students do not passively absorb information but rather meaningful learning that involves the active creation and modification of knowledge structures [33]. When students are learning about science, they use their prior knowledge, beliefs, interests and goals to interpret all new information. In this way, the individual's conceptual scheme is progressively reconstructed as he or she becomes exposed to new experiences and ideas [34].

The cognitive constructivist theory was developed from the foundations of Jean Piaget, who emphasized the importance of the cognitive processes that occur within individuals as they interact with the environment around them [35]. This researcher suggested that through processes of accommodation and assimilation, individuals construct new knowledge from their experiences. When individuals assimilate new content, they incorporate the new experience into an already existing framework without changing that framework.

According to this theory, accommodation is the process of reframing one's mental representation of the external world to fit new experiences. Though constructivism is not a specific pedagogy, an educational theory inspired by Piaget's constructivism was developed by [36], who believed that students experience learning through activity towards a given goal while cognitive understanding will be constructed within learners' mind. Piaget calls this 'cognitive adventure'. At the core of this learning process are repetition, regularities, invariants and rules.
Social constructivism, developed from the ideas of Vygotsky in 1934, emphasizes the importance of society, culture and language [37]. According to this viewpoint, knowledge is socially constructed and learning takes place in particular social and cultural contexts. These are central to Vygotsky's perspective as it is to the zone of proximal development, in which an individual is capable of using his/her cognitive ability to solve his/her own problem with a mediator for guiding purposes [39]. Social interaction provides learners with ways of interpreting the physical and social world, thus they become acculturated into ways of thinking that are common practice in that specific community. In reality, much learning occurs when students interact with more competent individuals such as adults and teachers.

Through a process of scaffolding, a teacher can gradually guide students to develop their knowledge and skills while making connections with students' existing schemes. The emphasis is on a communication-rich environment in which students are given opportunities to interact with adults and peers in order to negotiate meaning. According to this view, teachers have a central role in providing guidance and support to learners.

\section{The Case of Macao, China}

In Macao, there is no common curriculum for computer literacy courses. Different schools teach them based on their own established traditions within their institutional culture. This becomes problematic when evaluating students' computer literacy skills. Macao teachers typically use the force-feeding approach to teach their students so that teachers and schools can easily claim that students have acquired a lot of knowledge and skills.

By definition, force-feeding is a teaching method in which students are deluged with knowledge, content and exam-requirements to strengthen their abilities in answering exam questions. Within several weeks, students are then required to undergo tests of such knowledge. According to [40], students feel tired and reluctant to learn and, hence, they can easily be cognitively overloaded. This might be a possible explanation why Macao students do not appear to be applying computer skills in real life and why some seem to lost interest in computer literacy classes [41]. In line with our experience, teachers of other subjects often report that their computer skills are not transferable because students are unable to apply their computer literacy skills to perform tasks in their classes or in real life. Some teachers even report that students have totally forgotten much of what they had learnt in computer literacy courses. For [40], another possible reason is because computer literacy training is often not aligned with the teaching objectives that incorporate elements of 
realistic application. [40] commented that current learning methods typically used in Macao are not suitable for the rapidly evolving environment of nowadays' world information technology.

Usually, computer literacy classes often comprise, at least, 30 students, so very little individual attention can be given to each student to address their own problems. Moreover, best practice strongly indicates the need to change to a more skill and competency-focused curriculum, so that students develop real world computer skills effectively, including problem-based teaching methods that require significantly more individual teaching by the instructor. One way of providing this relies on the introduction of peer-tutors, which involves successful graduates from previous courses as instructors for successive cohorts of students. Most probably, this approach would significantly reduce the teacher's workload by employing less expensive instructors. By involving a tutor, the earlier stage of learning may be reinforced and, if so, a raise of the overall performance can be enhanced.

\section{Confucian Heritage Culture}

The term Confucian Heritage Culture (CHC) is named after Confucius, the most famous ancient Chinese philosopher and teacher who lived about 500 B.C. He taught morality as a basis for social structure within relationships of mutual dependency. Whereas western social structures are based on the rule of law, Confucian social structure is based on bonds. Confucius acknowledged differences in natural talent and believed in encouraging or pushing talented students, regardless of wealth or family status [42]. Meritocracy and egalitarianism were encouraged.

Confucianism cross-fertilized with the Daoism of Laozi, Zhuangzi and other philosophies. Laozi's poem ('The Way of Virtue') is a philosophical writing in nature that encouraged questioning, looking at problems in fresh ways by reinforcing students to become honest and upright [43]. However, the Imperial Civil Service Examination System, established in the Han Dynasty (only abandoned in the twentieth century), shifted the emphasis of education away from this questioning direction [44].

Still, this exam system has profound effects even nowadays. Established to recruit men eligible for high official positions, it was characterized by a rigid hierarchy of exams and extreme centralization [45]. The exam was based on memorization of the classics and was an institutionalized way to rise above one's station to where the benefits of success were enormous. However, success in the exams was expensive, time-consuming and demanding both physically and psychologically. Much cheating took place while crib notes and essays from previous exams were sold. Creativity in the western sense was discouraged [44].

Many have argued that the role of the Chinese language in learning is important because of its character-based nature, instead of being alphabetbased, encouraging attention to detail, memorization and relating visual parts to the whole. It creates a learner who is good at mathematics and visual performance [45]. Students learn that 'practice makes perfect'.

The role of the teacher in modern Chinese society owes its influence to Confucian ideals. 'Teachers' Day' is celebrated on Confucius's birthday and was for many years a national holiday in Taiwan. Teachers are respected, not challenged or questioned and are seen as surrogate parents [47].

To contrast western assumptions about learning and education with Chinese ideals [48], western society has been described as being influenced by Judeo-Christian notions of individuality, progress and creative thinking. There is an assumption that many things are unknown, especially in the field of science. Argumentation is one of the basic ways of furthering knowledge. There are no 'right' answers. Teachers are given much less respect and are seen as facilitators of learning [48].

Today, CHC learners have three specific key values, namely co-operation, the concept of 'face' and self-effacement [50]. This co-operation system operates inside and outside the classroom, as noted by [50], who report on the perceptions of Chinese kindergarten teachers: "In Chinese society and in the classroom, the priorities are that each person must be part of a group or community; learning interdependency, co-operation and social awareness". [49] also states that: "Within the Confucian tradition, students learn through co-operation, by working for the common good, by supporting each other and by not elevating themselves above others."

This same reluctance to openly challenge authority and express opinions is also manifested in students' relationships towards their peers. Being very supportive of one another, students tend to dislike individual critical feedback on their peers' work in the presence of the whole class. Just as Chinese students do not like to lose face by making incorrect responses, they will do their best to prevent the same from happening to their peers.

The concept of self-effacement also stems from the Confucian principle of decency, which requires that individuals maintain a certain level of humility (in accordance with their social rank) and do not elevate themselves above others. [46] Notes that Chinese people consistently describe themselves in less positive terms than Americans and suggests that this conception of the Self probably reflects their society's need for modesty and balance. This concern for humility, however, can be counterproductive in a learning situation when one is trying 
to elicit evaluative comments. [51] Observed that Chinese students would invariably downplay their own performance by giving such remarks as "I didn't prepare well", when this was certainly not the case.

\section{Cognitive Scaffolding}

Cognitive scaffolding in computer literacy learning is based on two main approaches: humancomputer interface or user-interface and humanhuman interface [52]. Human-computer involves the use of software that can be found either online (webbased) or offline (user-interface). It provides learners with guidelines and exercises on a particular piece of software. Once a student has the ability to identify the problem and seek help correctly, a humancomputer interface can provide effective computer literacy learning. Despite the benefits of it, humanhuman tutoring offers a valuable model for identifying effective tutorial strategies, as the richness of human dialog is difficult for computers to extract and imitate [52]. It does not just provide guidelines and assistance in using the software by helping learners to decompose and identify problems; it also provides support and encouragement for further attempts to learn.

Rethinking scaffolding in the information age is one of the main principles of Vygotskian theory related to the notion of a zone of proximal development (ZPD), which was conceptualized as the distance between the actual developmental level (as determined by independent problem solving) and the level of potential development (as determined through problem-solving under adult guidance or in collaboration with more capable peers). [38] Trusts that guided interactions with an adult or a more skilled peer could facilitate a higher level of thinking within the zone. This author's ideas have been the subject of much research over the years [53].

Scaffolding is a concept closely related to the idea of ZPD. Scaffolding means changing the level of support. Over the course of a teaching session, a more skilled peer adjusts the amount of guidance to fit the student's current performance. Dialog becomes an important tool of this process under the ZPD scope. In a dialog, a student showing unsystematic, disorganized and spontaneous concepts requires more intervention from skilled helpers than a student with more systematic, logical and rational concepts [38].

\section{Work in Progress}

The present ongoing research will try to investigate two aspects of the teaching process in Macao, China: reassigning the teacher role by the introduction of peer-tutors and the understanding of how computer literacy can be learnt in a Chinese cultural background.
By introducing peer-tutoring, the teacher no longer acts as the sole source of information. His/her role should be re-conceptualized as a facilitator, a planner, a coach, a consultant and a communicator, determining how much complexity and detail is necessary to make the learning activities meaningful [54]. The peer-tutor role typically focuses on curriculum content, matching more closely a hierarchical teacher-student relationship than a more coequal student-student relationship.

Memorizing keywords and procedural steps make part of the common learning approach for traditional education in Macao, allowing students to gain temporary knowledge and with difficulties for students to be able to apply that knowledge in real life.

As expected, the local students of Macao are mostly Chinese and are a result of the traditional spoon-feeding educational background, where many students hold difficulties in doing challenging questions on their exams. These challengers usually require higher-order and logical thinking. Spoonfeeding learning technique is unable to cope with such challenging questions. By implementing peertutors, teachers gain insight into how the teaching materials interact with students' learning experience, providing another way of communication among class-participants.

Certainly, the key research question for this project becomes as follows: To what extent might the effective use of peer-tutoring improve the quality of teaching and learning with computer literacy courses in an university setting without significantly increase the cost of provision? In a more detailed perspective, Table 1 shows the main areas of enquiry covered by this global research while Figure 1 illustrates the action research cycle to be developed in the coming months.

Table 1 Sub-questions generated from the main one

\begin{tabular}{|l|}
\hline How to improve the quality of learning? \\
\hline $\begin{array}{l}\text { To what extent does the learning context influence the } \\
\text { learning approaches? How well do students learn in a } \\
\text { class with peer-tutors comparing with the } \\
\text { conventional approach? }\end{array}$ \\
\hline How satisfied are students with peer-tutoring? \\
\hline $\begin{array}{l}\text { How do different types of learning environments } \\
\text { influence students' learning? }\end{array}$ \\
\hline $\begin{array}{l}\text { How do different online resources affect their } \\
\text { learning? How do their peers affect their learning? }\end{array}$ \\
\hline $\begin{array}{l}\text { What influences and side-effects would peer- } \\
\text { tutoring provides as far as the university's future } \\
\text { development is concerned? }\end{array}$ \\
\hline $\begin{array}{l}\text { What differences can be expected with new teaching } \\
\text { approaches within computer literacy courses? }\end{array}$ \\
\hline
\end{tabular}

The methodology designed for this study combines both qualitative and quantitative techniques. It consists of a survey and an intervention by the researchers, emphasizing action 
that could improve teaching and learning practices. This aim directly addresses the computer literacy skills only. It is expected to provide practical answers to institutions implementing a peer-tutoring program and to contribute to the design of collaborative learning in classrooms.

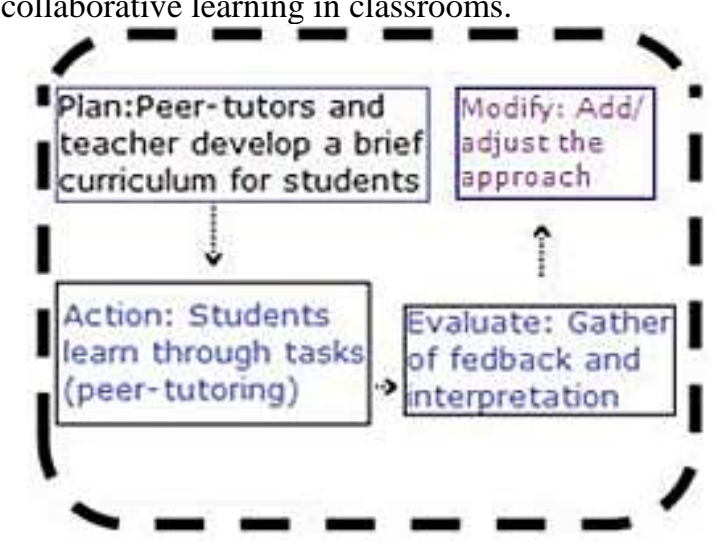

Figure 1. This action research involves a revision (evaluation) period and a re-cycle enhancement

It is expected that the use of a multiinstrumentation design will strengthen the conclusions of this ongoing project which includes the following six items:

- Questionnaires will be used to gather data concerning issues of working in teams. Both closed and open questions will be asked in order to verify the improvements as well as to investigate further improvements on the teaching approach.

- Participant observation. Field notes of students at work will be used to record events and activities in the classrooms.

- Student journals will be exploited to survey respondents' attitudes and views. These responses will identify new and specific questions that can be addressed in interviews, providing an accurate record of the participants thinking process.

- Semi-structured interviews will be held with focus on groups.

- Action learning workshops will provide peertutors with the opportunity to explore in-depth concerns and perceptions before and after each intervention.

- Grading of assignment tasks provided by the peer-tutors.

\section{Last Considerations}

Computers and information technologies are evolving rapidly. Consequently, computer literacy courses ought to respond to these high demands from the industry by teaching the necessary relevant content. Universities should continuously equip students with relevant abilities and preparing them for the real world. However, traditional teaching processes seem to be struggling to provide these requests. Many frustrations appear to have restricted students from learning such skills. On the other hand, the use of peer-tutoring as a teaching method is not new in education. Therefore, these theories can be applied on the teaching of computer literacy in order to meet the high demand from the outside world.

To write software for learning purposes is both costly and time-consuming. Moreover, this software may only last a couple of years as the technology changes so rapidly. Few years later, students may require updated software.

Prior to the year 2000, lacking knowledge of computer literacy was considered to be normal, so that application-based teaching was effective for students' improvement [54]. Since then, definitions of computer literacy have been updated and this became an unstoppable trend. Recently, computer literacy has moved beyond technical competency toward a critical understanding of what students' encounter in cyberspace. Certainly, the development of technology continues to reshape the definition of computer literacy including the international standardized computer certifications.

\section{References}

[1] Norman, D. A., (1984). "Worsening the Knowledge Gap" Annals of the New York Academy of Sciences, 426(1), 220-233.

[2] Besser, H., (1993). "Education as Marketplace" Computers in Education: Social, Political, and Historical Perspectives, 37-69.

[3] Childers, S., (2003). "Computer Literacy: Necessity or Buzzword?" Faculty Publications, UNL Libraries, 90.

[4] Murray, M., Sherburn, R. \& Pérez, J., (2007). "Information Technology Literacy in the Workplace: A Preliminary Investigation".

[5] Grant, D. Malloy, A. D. \& Murphy, M. C., (2009). “A Comparison of Student Perceptions of Their Computer Skills to Their Actual Abilities" Journal of Information Technology Education, 8, 141-160.

[6] Boutin, F., Chinien, C., Moratis, L. \& Baalen, P., (2009). "Overview: Changing Economic Environment and Workplace Requirements: Implications for ReEngineering TVET for Prosperity" International Handbook of Education for the Changing World of Work, 81-96.

[7] Gupta, G., (2006). "Computer Literacy: Essential in Today's Computer-Centric World" ACM SIGCSE Bulletin, 38(2), 115-119.

[8] Gibbs, S. \& McKinnon, A. (2009). "The Computing Skills Expected of Business Graduates: a New Zealand Study". 
[9] Kellner, D., (2006). "Technological Transformation, Multiple Literacies and the Re-visioning of Education" The International Handbook of Virtual Learning Environments, 241-268.

[10] Temmerman, N. (2006). "Equipping Future Arts Educators for Primary Schools of the 21st Century: An Australian Point of View" International Journal of Music Education, 24(3), 271.

[11] Oliveira, F., Negreiros, J. "Constraints of Learning Mathematics: A Systemic Historical Review of the Literature" Research and Education, ISSN 1678-4634, Vol 41 (3), University of São Paulo, Brazil (Sep 15).

[12] Kvasny, L., Joshi, K. \& Trauth, E., (2011). "The Influence of Self-efficacy, Gender Stereotypes and the Importance of it Skills on College Students' Intentions to Pursue IT Careers" In Proceedings of the 2011 iConference (pp. 508-513).

[13] Csapo, N., (2002). "Certification of Computer Literacy" The Journal.

[14] Johnson, Bartholomew \& Miller (2006). "Improving Computer Literacy of Business Management Majors: A Case Study" Journal of Information Technology Education, 5, 77-94.

[15] Chan (2009). "A Study on Effectiveness of ProjectBased Learning in Computer Teaching (unpublished master dissertation)" University of Macau, China.

[16] Cheung, K., (2006). "Cognitive Overload Theory: New Vision for Teaching Design” (認知負荷理論: 教學 設計研究的新視覺). 教學新論 2006 51-53, 51-53.

[17] Oliveira, F., Negreiros, J., Neves, A. "A Contribution from Macao, China, on Teaching Mathematics" International Journal of Education and Research, Vol. 3 (11), pp. 189-208, ISSN 2411-5681 (Nov 15).

[18] Wagner, L., (1982). "Peer Teaching: Historical Perspectives" Greenwood Press Westport, CT.

[19] MacPherson, K., (1999). "The Development of Critical Thinking Skills in Undergraduate Supervisory Management Units: Efficacy of Student Peer Assessment" Assessment \& Evaluation in Higher Education, 24(3), 273-284.

[20] Evans, W., Flower, J. \& Holton, D., (2001). "Peertutoring in First-year Undergraduate Mathematics" International Journal of Mathematical Education in Science and Technology, 32(2), 161-173.

[21] Kourea, L., Cartledge, G. \& Musti-Rao, S., (2007). "Improving the Reading Skills of Urban Elementary Students Through Total Class Peer-tutoring" Remedial and Special Education, 28(2), 95.

[22] Verba, M., (1998). “Tutoring Interactions Between Young Children: How Symmetry Can Modify Asymmetrical Interactions" International Journal of Behavioral Development, 22(1), 195-216.
[23] Greenwood, C., Delquadri, J. \& Hall, R., (1989). "Longitudinal Effects of Class Wide Peer-tutoring" Journal of Educational Psychology, 81(3), 371-383.

[24] Fantuzzo, J, Riggio, R., Connelly, S. \& Dimeff, L., (1989) "Effects of Reciprocal Peer-tutoring on Academic Achievement and Psychological Adjustment: A Component Analysis" Journal of Educational Psychology, 81(2), 173.

[25] Calhoon, M. \& Fuchs, L., (2003). "The Effects of Peer-Assisted Learning Strategies and Curriculum-Based Measurement on the Mathematics Performance of Secondary Students with Disabilities" Remedial and Special Education, 24(4), 235-245.

[26] Fuchs, L., Fuchs, D. \& Kazdan, S., (1999). "Effects of Peer-assisted Learning Strategies on High School Students with Serious Reading Problems" Remedial and Special Education, 20(5), 309.

[27] Fantuzzo, J., Dimeff, L. \& Fox, S., (1989). "Reciprocal Peer-tutoring: A Multimodal Assessment of Effectiveness with College Students" Teaching of Psychology, 16(3), 133-135.

[28] Nestel, D. \& Kidd, J., (2003). "Peer-tutoring in Patient-Centered Interviewing Skills: Experience of a Project for First-year Students" Medical Teacher, 25(4), 398-403.

[29] Alsup, J., Conard-Salvo, T. \& Peters, S., (2008). "Tutoring Is Real: The Benefits of the Peer-tutor Experience for Future English Educators. Pedagogy: Critical Approaches to Teaching Literature" Language, Composition and Culture, 8(2), 327.

[30] Wiskochil, B., Lieberman, L., Houston-Wilson, C. \& Petersen, S., (2007). "The Effects of Trained Peer-tutors on Academic Learning Time: Physical Education for Children Who Are Blind" Journal of Visual Impairment \& Blindness, 101(6), 339-350.

[31] Dufrene, B., Noell, G., Gilbertson, D. \& Duhon, G., (2005). "Monitoring Implementation of Reciprocal Peertutoring: Identifying and Intervening with Students Who Do Not Maintain Accurate Implementation" School Psychology Review, 34(1), 74-87.

[32] Negreiros, J., Oliveira, F. "Contemplation on Today's Digital Education" World CIST - New Contributions in Information Systems and Technologies (Volume I), Springer, pp. 1213-1220, ISBN 978-3-319-16486-1 (Apr $15)$.

[33] Carey, S., (1985). "Conceptual Change in Childhood” Bradford. MIT Press, Cambridge, MA.

[34] Driver, R., (1989). "Students' Conceptions and the Learning of Science" Int. Journal Science Education, 11, 481.

[35] Piaget, J., (1999). "The Construction of Reality in the Child" (Vol. 20). Psychology Press. 
[36] Papert, S., (1982). “An Interpretation of Piaget's Constructivism" Revue Internationale de Philosophie, 36(4), 612-635.

[37] Lemke, J. L., (2001). "Articulating Communities: Sociocultural Perspectives on Science Education" Journal of Research in Science Teaching, 38(3), 296-316.

[38] Vygotsky, L., (1978). "Mind in Society: The Development of Higher Mental Functions" Cambridge, MA: Harvard University Press.

[39] ISTE, R., (2000). "Research on Technology in Education" Verfügbar Unter.

[40] Heuer, B. \& King, K., (2004). "Leading the Band: The Role of the Instructor in Online Learning for Educators" The Journal of Interactive Online Learning, $3(1), 1-11$

[41] Thota, N., Negreiros, J. "Introducing Educational Technologies to Teachers in Macao, China: Experience Report" Journal of University Teaching \& Learning Practice, Vol 12 (1), ISSN 1449-9789, Australia (Feb 15).

[42] Hoffman, M. \& Blake, J., (2003). "Computer Literacy: Today and Tomorrow" Journal of Computing Sciences in

Colleges, 18(5), 221-233.

[42] Lee (1996). "The Cultural Context for Chinese Learners: Conceptions of Learning in the Confucian Tradition" The Chinese Learner: Cultural, Psychological and Contextual Influences, 34, 63-67.

[43] Dong, Y., (1996). "Lao Zi's Thought and Contemporary Chinese Higher Education East-West Dialogue" Knowledge and Higher Education, 280.

[44] Cleverley, J., (1985). "The Schooling of China: Tradition and Modernity in Chinese Education" Allen \& Unwin Sydney. Retrieved from library.wur.nl/WebQuery/ clc/1661198.

[45] Hayhoe, R., (1984). "Contemporary Chinese Education" ME Sharpe Armonk, NY. Retrieved from library.wur.nl/ WebQuery/clc/249595.

[46] Bond (1991). "Beyond the Chinese Face: Insights from Psychology" Oxford University Press, Hong Kong.

[47] Gow, L., Balla, J., \& Hau, K. T., (1996). "The Learning Approaches of Chinese People: A Function of Socialization Processes and the Context of Learning?" Retrieved from psycnet.apa.org/psycinfo/1996-98234-008.

[48] Jin, L., \& Cortazzi, M., (1998). "The Culture the Learner Brings: A Bridge or a Barrier?” na.

[49] Nelson, G., (1995). "Cultural Differences in Learning Styles. Learning Styles in the ESL 1EFL Classroom" Boston: Heinle \& Heinle Publishers, 3-18.

[50] Cortazzi, M., \& Jin, L., (1996). "Cultures of Learning: Language Classrooms in China" Society and the Language Classroom, 169, 206.
[51] Flowerdew, L., (1998). "A Cultural Perspective on Group Work” ELT Journal, 52(4), 323-329.

[52] Chalmers, P. A., (2003). The Role of Cognitive Theory in Human-Computer Interface" Computers in Human Behavior, 19(5), 593-607.

[53] Rogoff, B., (1990). "Apprenticeship in Thinking: Cognitive Development in Social Context" Oxford University Press.

[54] Zelia, B., Negreiros, J. "The Portuguese School of Macao, China: A Traditional/Web 2.0 Assessment Facing Different Learning Styles" Handbook of Research on Enterprise 2.0: Technological, Social and Organizational Dimensions, Cunha, M., Moreira, F., Varajão, J. (Eds), Chap. 23, pp. 428-449, ISBN 978-1-4666-4375-8, IGI Global-Hershey, PA: Information Science Reference (Sep 13) 